\title{
Dorsoventral pattern formation of tobacco leaf involves spatial expression of a tobacco homeobox gene, NTH15
}

\author{
Masanori Tamaoki*, Yutaka Sato, and Makoto Matsuoka \\ Nagoya University, BioScience Center, Chikusa, Nagoya 464-01, Japan
}

(Received 7 December 1996, accepted 28 January 1997)

\begin{abstract}
Biological function of a tobacco homeobox gene, NTH15, was studied by producing two different types of transgenic tobacco, one of which was transformed with NTH15::GUS and the other was transformed with CaMV 35S promoter::antisense NTH15. The GUS staining around shoot apical meristem (SAM) in transgenic plants with NTH15::GUS revealed that the NTH15 expression is specifically localized in the dorsal region of young leaf primordia. The transgenic plants transformed with the antisense construct lost the expression of the endogenous transcript around SAM and also showed alterations in leaf morphology. These transformants formed leaves with disorganized pinnate venation. Midribs of the malformed leaves also lost crescent-shaped vascular systems by ectopic cell vacuolization in their adaxial side. These observations suggest suppression of the NTH15 expression around SAM causes loss of dorsoventrality in midribs. Taken together with the observations of the NTH15 expression pattern, it may be important for the dorsoventral development of leaves that the NTH15 gene is expressed in the adaxial side of young leaf primordia.
\end{abstract}

\section{INTRODUCTION}

A leaf primordium is initiated, as a buttress, from the flanking region of shoot apical meristem (SAM) during plant development (Poethig and Sussex, 1985). In the vegetative phase, SAM can produce two kinds of lateral organs, leaf primordium and primordium of axillary bud (Snow and Snow, 1947). The morphological difference of these organs is clearly realized by a character, dorsoventrality. Axillary buds are formed by the radial pattern formation, which results symmetrical feature as same as stems. Leaves of most plants are flattened shape, which is considered an adaptation to their photosynthetic role, and the face and back of many leaves are clearly distinguished. Thus, dorsoventral pattern formation is one of the most essential feature of leaf morphology (Steeves and Sussex, 1989).

By histological studies of dicotyledonous plants, the flattened shape of leaf results from two major shifts in the pattern of early development (Avery, 1933; Poethig and Sussex, 1985; Foster, 1936). The first shift occurs in a small group of cells on the flank of SAM, in which the polarity of cell divisions are changed. This contributes to the formation of a leaf primordium with the first axis of leaf, proximodistal axis, along the midrib in the mature leaf (Waites and Hudson, 1995). The second shift occurs in the dorsal side of the leaf primordium, where the lateral

\footnotetext{
* Corresponding author.
}

cell divisions are started to form the laminae. At this stage, no lateral growth can be observed in cells towards the ventral (abaxial) side of leaf primordium, suggesting that the establishment of leaf dorsoventrality coordinates the formation of the leaf laminae.

Many mutations affecting the process of leaf development have been described (Marx, 1983; Sinnott, 1960; Caruso, 1968; Meicenheimer et al., 1983). For example, mutations at the phantastica (phan) locus of Antirrhinum majus show loss of the dorsoventrality in leaves. Histological analysis of this mutant suggests that this gene is involved in determination of dorsal cell type in leaf primordium (Waites and Hudson, 1995). Although there are many reports about mutations that are involved in leaf development including the determination of the leaf dorsoventrality, very little is known about the molecular or biochemical mechanism of them.

Several dominant mutations that altered determination patterns of maize leaf blades have been described (Smith and Hake, 1992). The most extensively characterized mutation is KNOTTED1 (Kn1), that results in the formation of pocketed outgrowth (knots) on lateral veins of blade (Freeling and Hake, 1985). The Kn1 gene had been cloned by transposon tagging and its sequence revealed that the Kn1 gene encodes a homeodomain protein (Vollbrecht et al., 1991). At this time, many homeobox genes were isolated from various higher plants (Kerstetter et al., 1994), and analysis of these genes have helped to explain the relationship between their expression pat- 
terns in SAM and plant development, especially in leaf morphogenesis. We have found that expression of a tobacco homeobox gene, NTH15, is localized around SAM, and its ectopic expression in transgenic tobacco altered their leaf morphology (Tamaoki et al., unpublished results). The similar results were also observed in other homeobox genes from rice (Matsuoka et al., 1993; KanoMurakami et al., 1993), Arabidopsis (Lincoln et al., 1994) and maize (Sinha, et al., 1993; Jackson et al., 1994; Schneeberger et al., 1995). In contrast to the over-expression experiments, few experiments of loss-of-function experiment has been performed in plant homeobox genes. The earlier study by Long et al. (1995) have shown that loss-of-function of an Arabidopsis homeobox gene, shootmeristemless (stm) causes to fail SAM formation. This result lead us to expect that loss-of-function experiments of homeobox genes may demonstrate their roles for plant morphogenesis.

In this communication, we produced transgenic tobacco, in which the expression of NTH15 in SAM was suppressed by the introduced antisense construct. Such plant formed abnormal leaves without the dorsoventral characters. These results suggest that the NTH15 expression in the dorsal side may be involved in establishment of leaf dorsoventrality.

\section{MATERIALS AND METHODS}

Plant growth condition. Tobacco seeds (Nicotiana tabacum cv. Samsun NN) were sterilized in 5\% sodium hypochlorite for $5 \mathrm{~min}$ and cultivated on a germination medium (Murashige and Skoog salts with 1\% sucrose and $0.5 \%$ gelangum) under continuos light at $25^{\circ} \mathrm{C}$. The seedlings were transplanted to soil and grown at $25^{\circ} \mathrm{C}$ in a $16 \mathrm{~h}$ light and $8 \mathrm{~h}$ dark cycle.

Screening of genomic libraries. Nuclear genomic DNA was isolated from leaves of 60 days old tobacco plants. The DNA was partially digested with Sau3AI and enriched for fragments with about $20 \mathrm{~kb}$ by a sucrose gradient. The fragments were cloned into the BamHI site of EMBL3 (Stratagene). The SacI fragment of the NTH15 cDNA (460 bp) was used as a probe for screening the promoter region of NTH15. Screening was performed in $50 \%$ formamide, $6 \times \mathrm{SSC}, 5 \times$ Denhardt's, $0.5 \% \mathrm{SDS}$, and $0.1 \mathrm{mg} / \mathrm{ml}$ salmon sperm DNA at $42^{\circ} \mathrm{C}$ for 14 hour.

Sequence analysis. Nucleotide sequences were determined by the dideoxynucleotide chain-termination methods using an automated sequencing system (ABI 373A). Analysis of DNA sequence was carried out with GENETYX computer software (Software Kaihatsu Co., Japan).
RNA gel blot analysis. Total RNA was prepared from leaves and stems from wild-type and transgenic plants for gel blot analysis. $10 \mu \mathrm{g}$ of each RNA preparation was transferred to Hybond N (Amersham), and hybridized with the EcoRI/HindIII fragment of the NTH15 cDNA (580 bp) without the homeobox sequence to avoid crosshybridization with other homeobox genes. Hybridization were performed at $42^{\circ} \mathrm{C}$ in a solution containing $50 \%$ formamide, $5 \times \mathrm{SSC}, 0.02 \% \mathrm{SDS}, 0.1 \%$ N-lauroylsarcosine, and $1 \%$ blocking reagent (Beringer). Filters were washed in $2 \times \mathrm{SSC}, 0.1 \% \mathrm{SDS}$ at room temperature and then further washed in $0.2 \times \mathrm{SSC}, 0.1 \% \mathrm{SDS}$ at $65^{\circ} \mathrm{C}$.

In situ hybridization. Plant materials were fixed in $4 \%(\mathrm{w} / \mathrm{v})$ paraformaldehyde and $0.25 \%$ glutaraldehyde in $0.1 \mathrm{M}$ sodium phosphate buffer, $\mathrm{pH} 7.4$, overnight at $4^{\circ} \mathrm{C}$, dehydrated through a graded ethanol series and then a tbutanol series (Sass, 1958), and finally embedded in Paraplast Plus (Sherwood Medical). Microtome sections (7 - $10 \mu \mathrm{m}$ thick) were mounted on glass slides treated with Vectabond (Vector Labs). The sections of leaf were deparaffinized in xylene, rehydrated through a graded ethanol series and dried overnight prior to performing in situ hybridization.

Probes for in situ hybridization with digoxigenin-labeled sense or antisense RNA were produced from the NTH15 coding region without poly (A)-region. Hybridization and immunological detection of the hybridized probes were performed according to the method of Kouchi and Hata (1993).

Construction of chimeric genes and tobacco transformation. For construction of NTH15 promoter::GUS gene, the 3-kb SalI-SacI genomic fragment, which included the 5'-terminal sequence of the NTH15 cDNA, was cloned into pUC119 and the 5'-flanking region was amplified by PCR using M13 (-20) primer and the specific primer, which was designed from 5 -untranslated region of NTH15 cDNA, with BamHI linker (5'-GCGGATCCCTTTTTCTTTCTCTGAGT-3'). The PCR product was cloned into the SalI-BamHI site of pUC119, and the sequence was determined to ensure that base exchange had not occurred during PCR. Finally, the product was digested with SalI-BamHI, and inserted into SalI-BamHI site of pBI101 (Clontech Laboratories, Inc.) to make the NTH15::GUS fusion construct.

For high level expression of the antisense transcript, the 1.6-kb BamHI fragment of the cDNA clone was introduced into the BamHI site of pBI121 after deletion of the $\beta$ glucronidose to produce $35 \mathrm{~S}$ ::antisense NTH15 construct. Direction of the $1.6-\mathrm{kb}$ fragment was confirmed by some restriction enzymes, and then the construct with the antisense direction was used for tobacco transformation.

The fusion constructs were introduced into Agrobacterium tumefaciens LBA4404 by electroporation. 
Agrobacterium-mediated transformation of Nicotiana tabacum cv. Samsun NN was performed with leaf discs as previously reported (Matsuoka and Sanada, 1991). Transgenic plants were selected in a medium containing $100 \mathrm{mg} / \mathrm{l}$ of kanamycin.

Histochemical localization of GUS activity. Histochemical localization of GUS activity was carried out essentially as described by Matsuoka and Sanada (1991). Shoot apices were embedded in 5\% agar, and the agar block was sectioned $(50-70 \mu \mathrm{m})$ with a microslicer. Sections were placed in $50 \mathrm{mM}$ sodium phosphate buffer, pH 7.0, 20\% methanol, and $1 \mathrm{mM}$ 5-bromo-4-chloro3 -indolyl- $\beta$-D-glucuronide, then vacuum infiltrated for 20 min and incubated at $37^{\circ} \mathrm{C}$ until a blue color appeared (usually after $12 \mathrm{~h}$ ). An ethanol wash was performed to stop the reaction and remove chlorophyll.

\section{RESULTS}

Histochemical analysis of NTH15::GUS transformants. To address the expression pattern of NTH15, a chimeric NTH15::GUS fusion gene was introduced into tobacco. The NTH15 :: GUS gene was created by fusing the $5^{\prime}$ flanking region of the NTH15 gene to the coding region of $\beta$-glucuronidase (see Material and Methods). Twelve independent transgenic lines were regenerated, and the expression of the GUS activity in vegetative mer- istem was found in all transgenic plants. The expression pattern of the GUS activity in all T2 plants tested was identical to that in T1 plants; indicating that the GUS expression pattern is inherited in the next generation with linkage to the kanamycin-resistance. All transgenic lines showed GUS activity in shoot apex region. Intensive GUS staining was observed at the basal region of leaf primordia (Fig. 1A). The localization of the activity in the basal of leaf primordia were extended at the most proximal and internal part of leaf primordia, although no signal was found in the outer part of them. Cross section at the apex summit clearly showed that NTH15 was expressed at the inner part (dorsal side) of leaf primordia (Fig. 1B). The expression of GUS appeared to form a gradient (Fig. 1B). In each leaf primordium, the GUS activity in the dorsal side was stronger than that in the ventral side. It is noteworthy that strong expression of NTH15 was also observed at the predicted position of leaf primordium (P0), and the staining was inclined toward the dorsal side. Signals became weaker at the lower part of SAM, but the dorsal side of leaf primordia were also stained in this section (Fig. 1C). Success to have shown the same staining pattern in SAM strongly suggests that the signals in the dorsal side of leaf primordia reflect the expression of NTH15 in SAM.

We also analyzed the expression of NTH15 during floral development. Fig. 1D shows a longitudinal section of floral meristems. In this section, we can see two types of
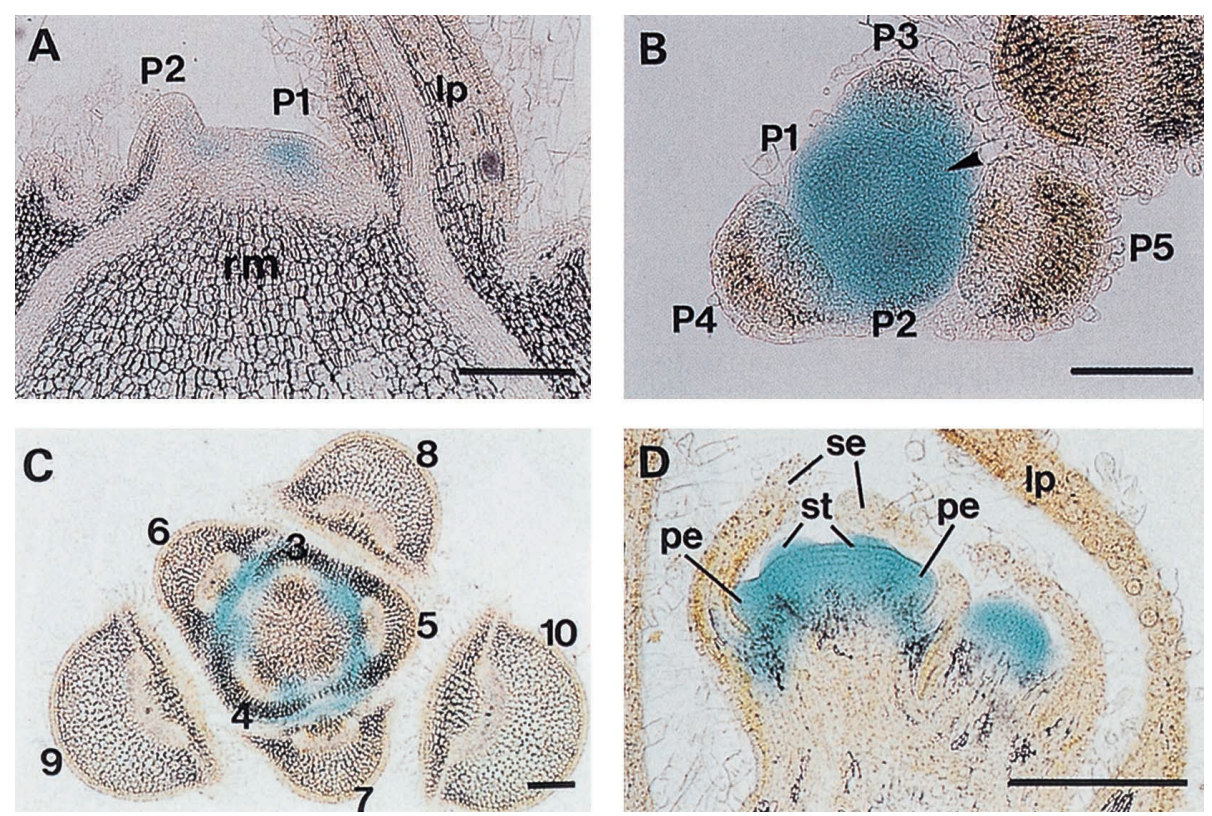

Fig. 1. Histochemical localization of GUS activity around shoot apices of NTH15::GUS transformants. (A), longitudinal section of a shoot apex from mature transgenic tobacco at vegetative stage. P1 and P2 leaf primordia are identified. (B), cross section of near the summit of SAM. Five leaf primordia are observed in this section (P1 to P5). Arrow head indicates P0 leaf. (C), cross section of a shoot apex region at lower part of (B), numbers indicate the order of leaf formation estimated from tobacco phyllotaxy. (D), longitudinal section of floral meristems. Early stage of floral meristem (right) and flower at the stage 5 (center) are found. rm, rib meristem; lp, leaf primordium; se, sepal; pe, petal; st, stamen. Bars, $100 \mu \mathrm{m}$ (A, B, C) and $1 \mathrm{~mm}(\mathrm{D})$. 
floral meristems at different stages. The earlier floral meristem is shown at the right side which approximately corresponds to the stage 2 of flower development, according to Kempin et al. (1993). At this stage, flat vegetative shoot apex has altered its morphology to a dome-like structure and the first sepal primordia arise (Mandel et al., 1992). At this stage, GUS activity was detected at the center of the incipient flower that will later give rise to the inner floral organs, but not in sepal primordia. At more advanced stage of flower meristem which has already formed petal primordia and stamen primordia, GUS activity was also shown at the center of the flower. At this stage, the expression of GUS was localized at the central part of floral primordium including petal and stamen primordia, but it was down-regulated in sepal primordia and the outermost region of petal.

\section{Phenotypic effects of the antisense NTH15 RNA on} leaf morphology. We also produced transgenic tobacco which expressed the antisense transcript of NTH15 controlled by the CaMV 35S promoter, and analyzed morphological alterations caused by decrease in the expression level of the endogenous NTH15. Twenty-three independent transformants were regenerated and almost all plants showed aberrant morphology of leaves (Fig. 2A, right). The transformants produced smaller, down-
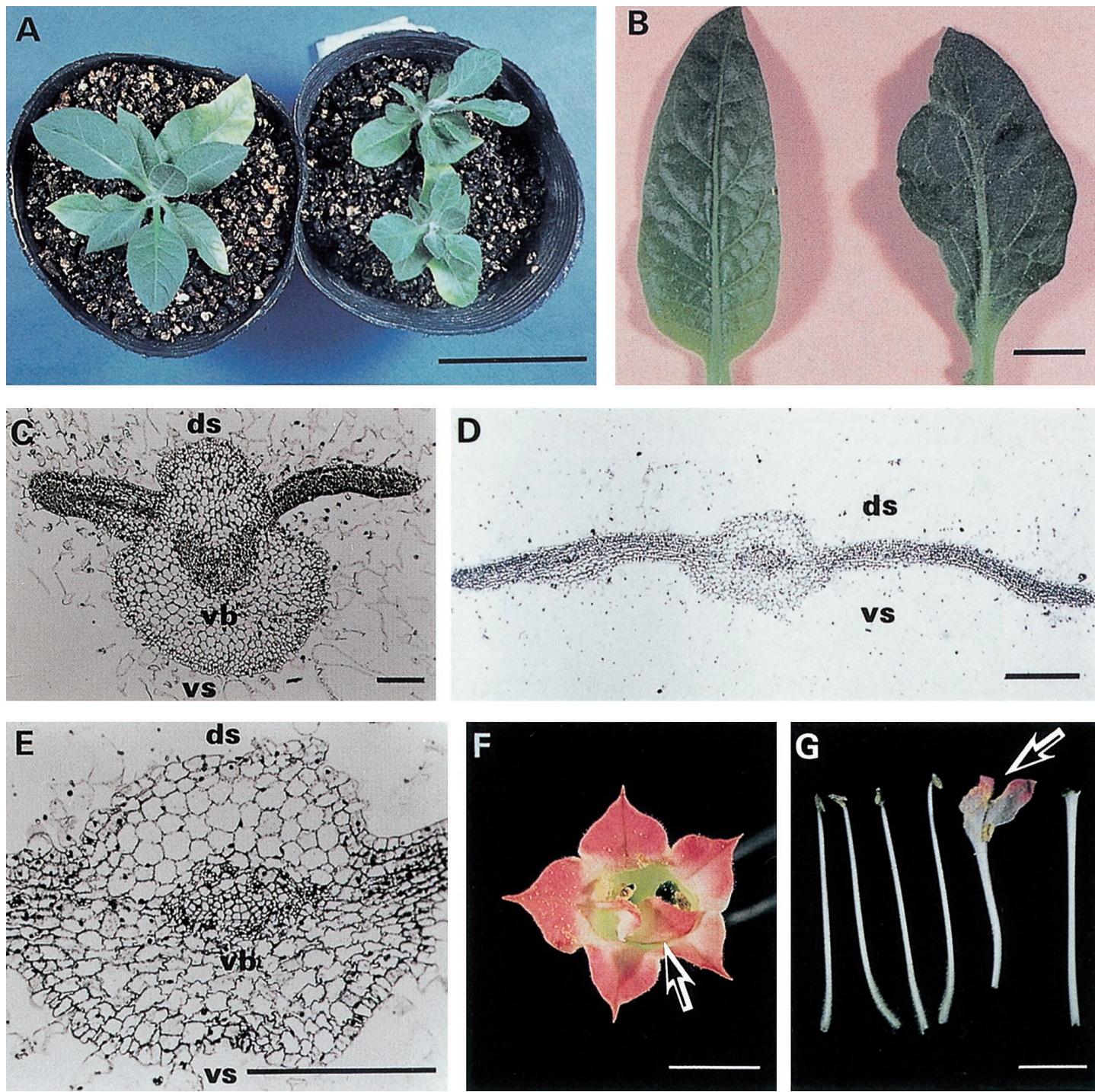

Fig. 2. Phenotypes of tobacco leaves in transgenic plants carrying the antisense NTH15 transgene. (A), top view of a wild-type (left) and transgenic plants (right). (B) Comparison of young leaves from a wild-type (left) and a transformant (right). (C), transverse section of a leaf primordium from wild-type. (D), transverse section of a leaf primordium from transgenic plant. (E), high magnification of the midrib in (D). (F), abnormal flower from a transgenic plant. (G), stamens and pistil of the abnormal flower. Petal/stamen mosaic is indicated by arrow. vs, ventral side; ds, dorsal side; vb, vascular bundle. Bars, $100 \mu \mathrm{m}(\mathrm{C}), 1 \mathrm{~mm}(\mathrm{D}, \mathrm{E}), 1 \mathrm{~cm}(\mathrm{~B}, \mathrm{~F}, \mathrm{G})$ and $5 \mathrm{~cm}(\mathrm{~A})$. 
angled leaves, relative to wild-type. Such abnormal morphologies were inherited to the next generations with the linkage to the kanamycin-resistance, and the transformants with the abnormal morphologies consistently showed lower content of the endogenous NTH15 transcript (see below). These results suggest that the abnormal morphologies were caused by the suppression of the endogenous NTH15 transcript by the transgene. Careful observation of the morphological alterations revealed two peculiar features in transgenic leaves. First, the pinnate venation with three to five secondary lateral veins were disorganized in the leaves of transformants (Fig. 2B, right), whereas the leaves in wild-type tobacco showed typical pinnate venation with seven to eight lateral veins (Fig. 2B, left). Second, more significantly, midribs in transgenic leaves were protuberant from surrounding leaf blades in comparison with wild-type leaves. In wild-type leaves, laminae develops from the dorsal side of midrib (Fig. 2C), resulting in mature leaves possessing the dorsoventral asymmetry across the midrib. The arising point of laminae in leaves of the transgenic plants was lower than that of wild-type plants (compare Fig. 2C, D). This causes the leaves in transgenic plants to be mirrorimage symmetry across the midrib. In addition to the arising point of laminae, there is another difference between transformants and non-transformants. In wildtype leaves, the vascular tissues of midrib were arranged in crescent-shape (Fig. 2C), but such arrangement had been lost in the midrib of transformant leaves (Fig. 2E). In the leaves of transgenic plants, the arrangement of vascular system in midrib became elliptic shape (phloem tissues encircled xylem tissues). These anatomies of transgenic leaves indicate that leaves of antisensetransformants lost dorsoventral characters.

The morphology of flowers in the transgenic plants was also changed. Although almost all flowers in T1 generation were normal, some of them formed ectopic petals in the third whorl (Fig. 2F). This flower had the normal number and morphology of sepals and petals, and the number of stamen was also normal, but some stamens were mosaics with exhibiting character of petals (Fig. 2G). Such abnormal morphology was inherited to the next generations with the linkage to the kanamycin-resistance, and the transformants with the abnormal morphologies consistently showed lower content of the endogenous NTH15 transcript (see below). Petal/stamen mosaic feature was also shown in flowers of a weak allele of shootmeristemless mutation ( $\mathrm{stm}$ ) in Arabidopsis, and this mutation is caused by loss-of-function of a kind of a Kn1type homeobox gene in Arabidopsis (Long et al., 1995; Clark et al., 1996). This similarity indicates that the morphologies of the transgenic plants are caused by the suppression of the endogenous transcript of NTH15.

The blot analysis with RNA demonstrated that NTH15 is mainly expressed in stem (Fig. 4B). Therefore, we ex-
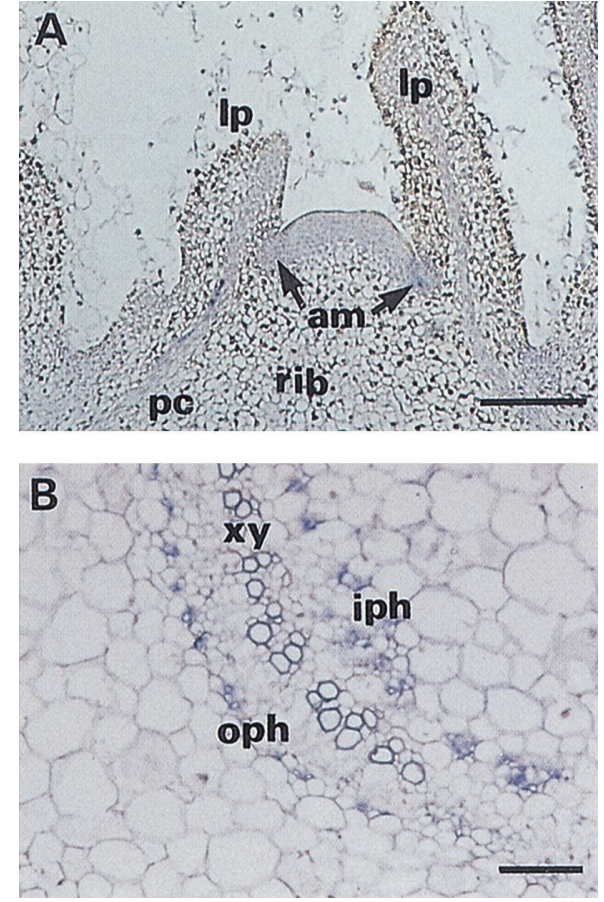

Fig. 3. Detection of the NTH15 transcript in shoot apex and stem of the antisense plant by in situ hybridization. (A), longitudinal section of a shoot apex of antisense plant. Very faint hybridization signal was observed around the shoot apex. (B), cross section of vegetative stem. Expression of NTH15 remained at the internal and external phloem. am, axillary meristem; lp, leaf primordium; pc, procambium; iph, inner phloem; oph, outer phloem; xy, xylem. Bars are equivalent to $100 \mu \mathrm{m}$.

pected that the growth or development of stem in the transformants with the antisense construct might be inhibited by the suppression of the endogenous transcript. However, morphological alteration was hardly detected as shown in the cross section of stem from the transformants (Fig. 3B). We directly tested whether or not the endogenous transcript was suppressed in the transgenic plants by in situ hybridization. Clear pin-point signals were detected in primary phloems of transgenic plants, while the signals were fainter than in wild-type tobacco (Fig. 3B). In contrast to stems, the expression of the endogenous transcript around SAM was significantly decreased in the transformants (Fig. 3A). The differences in the suppression level in different tissues were observed in all transformants we tested. These observations indicate that the remaining expression of the endogenous transcript in stem can cause normal development of stems in the transgenic plants while severe decreasing of its expression around SAM causes the abnormal development of leaves.

To examine the changes in the NTH15 mRNA level in the antisense transformants, we investigated the endogenous transcript and the antisense transcript in leaves and stems by RNA blot analysis. A band with $1.3 \mathrm{~kb}$, which corresponds to the size of the transgene, was de- 

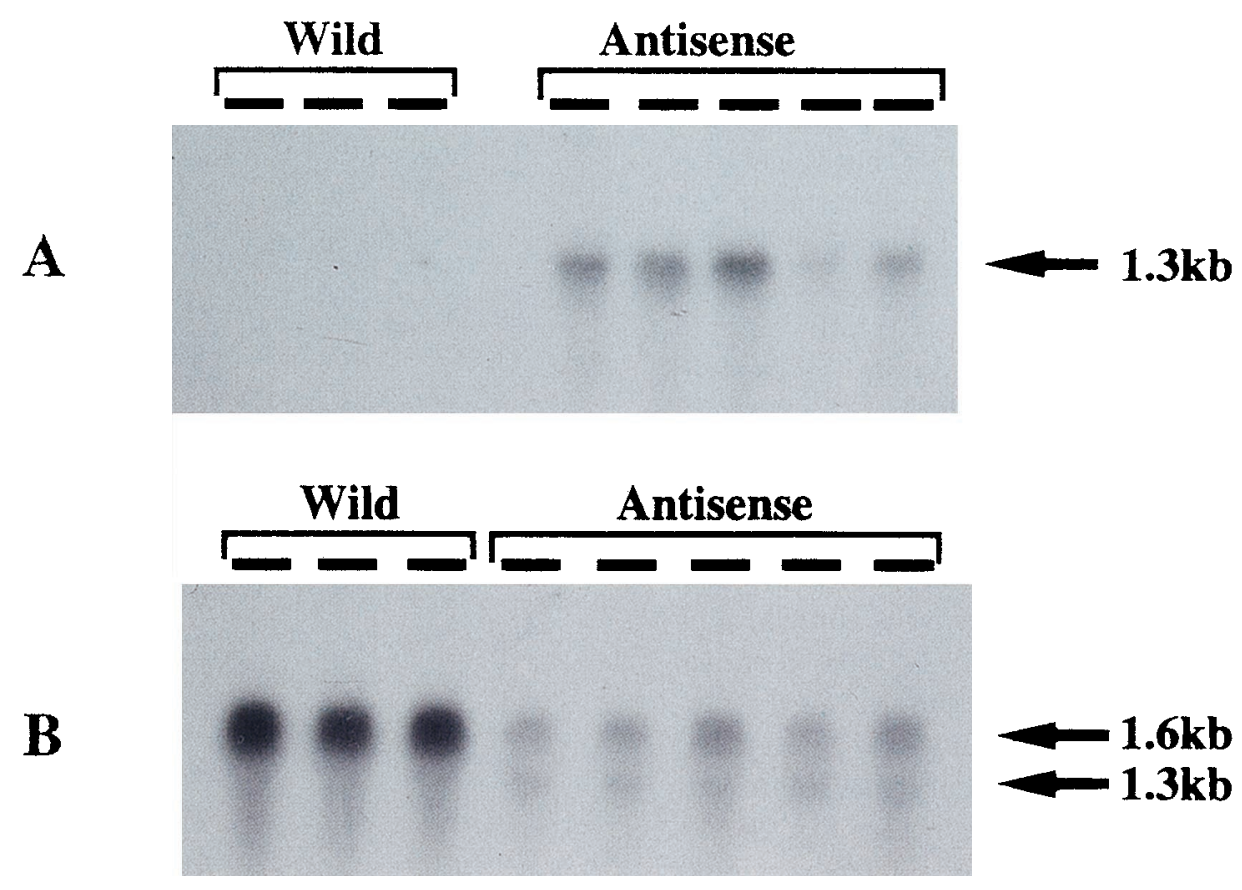

Fig. 4. Expression of NTH15 in antisense transgenic plants. RNA from leaves and stems were isolated from independent wild-type and antisense transgenic plants that formed abnormal leaves. Both RNA blots were probed with the ds-NTH15 sequence (see Material and Method). The bands with $1.3 \mathrm{~kb}$ correspond to the antisense transcript from the transgene and the bands with $1.6 \mathrm{~kb}$ correspond to the endogenous NTH15 gene (see text). (A), RNA blot analysis with leaf RNAs from wild plants and the transformants with the antisense NTH15 gene. The endogenous NTH15 expression was not observed in all leaves, while the $1.3 \mathrm{~kb}$ antisense transcript is found in all transgenic plants. (B), RNA blot analysis with stem RNAs from wild plants and the transformants with the antisense NTH15 gene. Signal of the endogenous transcript with $1.6 \mathrm{~kb}$ is observed in all plants, but expression level is decreased in antisense plants. Faint expression of the antisense transcript is also found in all antisense plants.

tected in leaves of the transformants but not in leaves of wild-type plants (Fig. 4A). The size of the endogenous NTH15 mRNA was estimated about $1.6 \mathrm{~kb}$ and its expression in leaves was hardly detected (Fig. 4A, B). Thus, the 1.3-kb bands in the transformant leaves correspond to the antisense transcripts from the transgene. In stem, high level expression of the NTH15 mRNA was observed at 1.6 $\mathrm{kb}$ in wild tobacco, while the $1.6-\mathrm{kb}$ transcript was dramatically decreased in stems of the transgenic plants. The 1.3-kb antisense transcript was also observed in stem but the amount of the antisense transcript was lower than the endogenous NTH15 mRNA (Fig. 4B). These results clearly show that the antisense transcript derived from the transgene suppressed the expression of the endogenous transcript in the transformants. Complete suppression of the endogenous transcript in stems had never been observed in all transgenic plants we tested (data not shown), suggesting that expression of NTH15 in stem may be essential for plant regeneration.

\section{DISCUSSION}

We have found that the NTH15 expression is localized in shoot apex and its ectopic expression causes some alterations in leaf morphology in transgenic tobacco (Tamaoki et al., unpublished results). These results suggest that the NTH15 expression in SAM involves in leaf development. In this report, we produced two kinds of transgenic tobacco, one of which was transformed with NTH15::GUS, and the other was transformed with the CaMV 35S::antisense NTH15 construct, to obtain further information for functional roles of NTH15 in tobacco.

Around SAM, the GUS activity controlled by the NTH15 promoter was localized in the dorsal side of $\mathrm{P} 1$ and $\mathrm{P} 2$ leaf primordia (Fig. 1A, B). The P1 leaf primordium is firstly identified from SAM as a buttress by a result of continued periclinal cell division in the flank of SAM (Cunninghame and Lyndon, 1986). The proximodistal axis of leaf, that will be represented in mature leaf by a line along midrib, is appeared at the P1 leaf, whereas the dorsoventrality is 
hardly observe at this stage. The first morphological evidence of the leaf dorsoventrality is observed in P2 leaf primordium in tobacco (McHale, 1993). At this stage, cells on the abaxial (ventral) side are enlarged by vacuolization to generate a midrib. In contrast, cells on the adaxial (dorsal) side of the primordium continue to divide rapidly and form flat plane tangential to SAM. Although the dorsoventrality in $\mathrm{P} 1$ primordium is unclear by anatomical observation, the expression of NTH15 is mainly localized at the dorsal side of $\mathrm{P} 1$ primordium, suggesting that the dorsoventrality in $\mathrm{P} 1$ primordium is already determined in terms of the NTH15 expression. Surgical experiments by Snow and Snow (1959) have shown that isolated pieces of P0 (the region where the next leaf will initiate) tissues can form dorsoventral leaves. This result indicates that the leaf dorsoventrality has been determined before the projection of leaf primordia. The expression of NTH15 at the predicted region of the dorsal side of $\mathrm{P} 0$ primordium also supports to this observation.

During the developmental process of leaf, the increase in length along the proximodistal axis is usually accompanied by an increase in width of midrib. A cambium-like region, in which cells divide tangentially, is developed at the adaxial side along the midrib. This cambium-like region is termed as adaxial meristem and it contributes to thickening of leaf midrib (Foster, 1936; Kaufman, 1959). Tangential cell divisions of the adaxial meristem also cause the formation of a crescent-shaped vascular bundle in midrib of wild leaf. In this adaxial meristem, unique cell files are found in wild-type leaf (Fig. 2C), but not in transformants (Fig. 2E), and the crescent-shaped vascular bundles in the midrib were not formed in the transgenic leaves. Instead of the adaxial meristem formation, cells in the adaxial side of transformants were expanded by vacuolization, same as at the abaxial side. Vacuolization mainly occurs in the cells of the abaxial side but not in the adaxial side. Such abnormal vacuolization at the adaxial side in transgenic plants suggests that the adaxial region lost the dorsal character and gained, in part, the ventral character. These phenomena lead us to speculate that decrease in the expression level of NTH15 in the adaxial side causes the loss of the dorsal character and change the dorsal character to the ventral.

Recently, Waites and Hudson (1995) proposed a model explaining the formation of leaf dorsoventrality by the genetical experiments with Antirrhinum. According to their model, the adaxial side of leaf is characterized by a dorsalising function (DF), and the abaxial side is established by a ventralising function (VF) in the process for determination of dorsoventrality in leaf. DF or VF is expressed in the adaxial or abaxial cells of the wild-type leaf primordia, respectively, and these functions are postulated to be antagonistically. Loss of the expression of NTH15 in the dorsal side of the transgenic leaves alters in their ventral characters to dorsal one. Such leaf alter- ation may be caused by ectopic expression of VF gene(s) in the dorsal side of leaf primordia by loss of the expression of NTH15. This speculation leads us to the possibility that the NTH15 product is a candidate of DF. Further studies must be done to test the possibility that NTH15 functions as a DF gene in leaf development of tobacco.

\section{REFERENCES}

Avery, G.S. (1933) Structure and development of the tobacco leaf. Am. J. Bot. 20, 565-592.

Caruso, J.L. (1968) Morphogenetic aspects of a leafless mutant in tomato. I. General patterns in development. Am. J. Bot. 55, 1169-1176.

Clark, S. E., Jacobson, S.E., Levin, J.Z., and Meyerowitz, E.M. (1996) The CLAVATA and SHOOTMERISTEMLESS loci competitively regulate meristem activity in Arabidopsis. Development 12, 1567-1575.

Cunninghame, M.G. and Lyndon, R.F. (1986) The relationship between the distribution of periclinal cell divisions in the shoot apex and leaf initiation. Ann. Bot. 57, 737-746.

Foster, A.S. (1936) Leaf differentiation in angiosperms. Bot. Rev. 2, 349-372.

Freeling, M. and Hake, S. (1985) Developmental genetics of mutants that specify knotted leaves in maize. Genetics 111, 617-634.

Jackson, D., Veite, B., and Hake, S. (1994) Expression of maize KNOTTED-1 related homeobox genes in the shoot apical meristem predicts patterns of morphogenesis in the vegetative shoot. Development 120, 405-413.

Kano-Murakami, Y., Yanai, T., Tagiri, A., and Matsuoka, M. (1993) A rice homeotic gene $O S H 1$, causes unusual phenotypes in transgenic tobacco. FEBS Lett. 334, 365-368.

Kaufman, P.B. (1959) Development of the shoot of Oryza sativa L.: II, Leaf histogenesis. Phytomorphology 9, 277-311.

Kempin, S.A., Mandel, M.A., and Yanofsky, M.F. (1993) Conversion perianth into reproductive organs by ectopic expression of the tobacco floral homeotic gene NAG1. Plant Physiol. 103, 1041-1046.

Kerstetter, R., Vollbrecht, E., Lowe, B., Veit, B., Yamaguchi, J., and Hake S. (1994) Sequence analysis and expression patterns divide the maize knotted1-like homeobox genes into two classes. Plant Cell 6, 1877-1887.

Kouchi, H. and Hata, S. (1993) Isolation and characterization of novel nodulin cDNAs representing genes expressed at early stages of soybean nodule development. Mol. Gen. Genet. 238, 106-119.

Lincoln, C., Long, J., Yamaguchi, J., Serikawa, K., and Hake, S. (1994) A knotted1-like homeobox gene in Arabidopsis is expressed in the vegetative meristem and dramatically alters leaf morphology when overexpressed in transgenic plants. Plant Cell 6, 1859-1876.

Long, J.A., Moan, E.I., Medford, J.I., and Barton, M.K. (1996) A member of the KNOTTED class of homeodomain proteins encoded by STM gene of Arabidopsis. Nature 379, 66-69.

Mandel, A.M., Bowman, J.L., Kempin, S.A., Ma, H., Meyerowitz, E.M., and Yanofsky, M.F. (1992) Manipulation of flower structure in transgenic tobacco. Cell 71, 133-143.

Marx, G.A. (1983) Developmental mutation in some annual seed plants. Annu. Rev. Plant Physiol. 34, 389-417.

Matsuoka, M. and Sanada, Y. (1991) Expression of photosynthetic genes from the $\mathrm{C}_{4}$ plant, maize, in tobacco. Mol. Gen. Genet. 225, 411-419.

Matsuoka, M., Ichikawa, H., Saito, A., Tada, Y., Fujimura, T., and 
M. TAMAOKI et al.

Kano-Murakami, Y. (1993) Expression of a rice homeobox gene causes altered morphology of transgenic plants. Plant Cell 5, 1039-1048.

McHale, N.A. (1993) LAM-1 and FAT genes control development of the leaf blade in Nicotiana sylvestris. Plant Cell 5, 10291038.

Meicenheimer, R. D., Muehlbauer, F. J., Hindman, J. L., and Gritton, E. T. (1983) Meristem characteristics of genetically modified pea (Pisum sativum) leaf primordia. Can. J. Bot. 61, 3430-3437.

Poethig, R.S. and Sussex, I.M. (1985) The developmental morphology and growth dynamics of the tobacco leaf. Planta 165, 158-169.

Sass, A.E. (1958) Botanical microtechnique, 3rd edition. Iowa State University Press, Ames, IA.

Schneeberger, R.G., Becraft, P.W., Hake, S., and Freeling, M. (1995) Ectopicexpression of the knox homeobox gene rough sheath 1 alters cell fate in the maize leaf. Genes Dev. 9, 2292-2304.
Sinha, N., Williams, R., and Hake, S. (1993) Overexpression of the maize homeobox gene, KNOTTED-1, causes a switch from determinate to indeterminate cell fates. Genes Dev. 7, 787795 .

Sinnott, E.W. (1960) Plant Morphogenesis. McGraw-Hill, New York.

Smith, L.G. and Hake, S. (1992) The initiation and determination of leaves. Plant Cell 4, 1017-1027.

Snow, M. and Snow, R. (1947) On the determination of leaves. New Phytol. 46, 5-19.

Steeves, T.A. and Sussex, I.M. (1989) Patterns in Plant Development, 2nd edition. Cambridge University Press, Cambridge.

Vollbrecht, E., Veit, B., Sinha, N., and Hake, S. (1991) The developmental gene Knotted-1 is a member of a maize homeobox gene family. Nature 350, 241-243.

Waites, R. and Hudson, A. (1995) phantastica: a gene required for dorsoventrality of leaves in Antirrhinum majus. Development 121, 2143-2154. 